\title{
Expression of Cytochrome Oxidases in Bacillus cereus: Effects of Oxygen Tension and Carbon Source
}

\author{
By J. E. ESCAMILlA, ${ }^{*}$ R. RAMiREZ, I. P. DEL ARENAL, G. ZARZOZA \\ AND V. LINARES \\ Instituto de Fisiologia Celular, Departamento de Microbiología, and Factultad de Medicina, \\ Departamento de Bioquímica, Universidad Nacional Autónoma de México, \\ Apartado Postal 70-242, 04510 México, DF
}

(Received 21 April 1987; revised 6 July 1987)

\begin{abstract}
The expression of three putative terminal oxidases (cytochromes $a a_{3}, o$ and $d$ ) of Bacillus cereus was studied in response to oxygen tension and the nature of the carbon source used for growth. High levels of cytochromes $b$ and $o$ were expressed irrespective of culture conditions. Oxygen deprivation caused a large drop in the levels of cytochromes $c$ and $a a_{3}$. Cytochrome $d$ appeared at low oxygen tensions, in anaerobic cultures and during slow aerobic.growth on poorly utilized carbon sources (casein hydrolysate). No cytochrome $d$ was detected during fast aerobic growth in fermentable (sucrose-containing) media or when $\mathrm{NaNO}_{3}$ was added to anaerobic cultures. Cytochromes $a a_{3}, o$ and $d$ were reduced by physiological substrates (NADH and succinate) and by ascorbate plus tetramethyl-p-phenylenediamine (TMPD). Oxidase activity using ascorbateTMPD as electron donor was significantly more resistant to cyanide inhibition in cells containing none or trace amounts of cytochrome $a a_{3}$. Thus, the involvement of cytochromes $o$ and $d$ in the cyanide-resistant respiration of Bacillus cereus is suggested.
\end{abstract}

\section{INTRODUCTION}

The complexity and diversity of bacterial respiratory systems has attracted the attention of many research workers in recent years (Poole, 1983). Significant variations in the composition and organization of the electron transport chains are observed in different species, and also within the same strain in response to environmental conditions. The respiratory systems of Bacillus spp. have not received much attention, even though $B$. subtilis was the first prokaryote that was examined for cytochromes (Poole, 1983). Early studies on Bacillus megaterium (Broberg \& Smith, 1967), B. subtilis (Tochikubo, 1971) and B. cereus (Felix \& Lundgren, 1973) revealed the presence of cytochromes $a, b$ and $a a_{3}$. The presence of cytochrome $o$ in $B$. megaterium (Broberg \& Smith, 1967), B. subtilis (Tochikubo, 1971) and B. cereus has also been suggested (Escamilla \& Benito, 1984). Although cytochrome $d$ (formerly called cytochrome $a_{2}$ ) has rarely been found in combination with cytochrome $a a_{3}$ (Poole, 1983), its presence in B. megaterium and $B$. cereus has been suggested by Hoggarth et al. (1977) and by ourselves (Escamilla \& Benito, 1984). Therefore, the regulation of the expression of the $B$. cereus respiratory system was further studied, in particular the expression of the three putative terminal oxidases (cytochromes $a a_{3}, o$ and $d$ ) in response to prevailing culture conditions.

\section{METHODS}

Organism and growth. A Bacillus cereus strain originally isolated by Andreoli et al. (1973) was grown in either modified $\mathrm{G}$ medium (Hanson et al., 1963) containing $0.2 \%$ yeast extract and $0.4 \%$ sucrose as fermentable carbon source, or a medium (Sterlini \& Mandelstam, 1969) free of fermentable sugars and containing $0.8 \%$ casein

Abbreviation: TMPD, tetramethyl-p-phenylenediamine. 
hydrolysate. $0 \cdot 32 \%$ L-glutamic acid, $0 \cdot 21 \%$ DL-alanine, $0 \cdot 12 \%$ L-asparagine and the metal salts mixture of G medium (Hanson et al., 1963) (final $\mathrm{pH}$ adjusted to $7 \cdot 1$ with $\mathrm{NaOH}$ ). Cultures were grown aerobically at $30^{\circ} \mathrm{C}$ in a 251 fermenter stirred at 250 r.p.m. and bubbled with 141 air min $^{-1}$. For oxygen-limited cultures, the medium was not sparged, but air $\left(141 \mathrm{~min}^{-1}\right)$ was passed through the gas phase of the vessel and agitation was adjusted to 500 r.p.m. For anaerobic growth, the medium was bubbled with oxygen-free nitrogen. Where indicated, anaerobic cultures (sucrose/yeast extract medium) were supplemented with $0 \cdot 15 \% \mathrm{NaNO}_{3}$. Aerobic cultures were inoculated with 1 litre of an actively growing culture from an orbital incubator (300 r.p.m.) while oxygen-limited and anaerobic cultures were inoculated with $500 \mathrm{ml}$ of a culture grown at $100 \mathrm{r} . \mathrm{p} . \mathrm{m}$. Cultures were harvested at the end of the exponential growth phase, and washed twice with cold $50 \mathrm{~mm}$-Tris/ $\mathrm{HCl}\left(\mathrm{pH} 7 \cdot 4\right.$ ) containing $5 \mathrm{mM}^{-\mathrm{CaCl}} \mathrm{Cl}_{2}$ and $5 \mathrm{mM}-\mathrm{MgCl}_{2}$ (TCM buffer). Cells were disrupted immediately or stored under liquid nitrogen.

Cell disruption and preparation of membrane fractions. Protease activity was prevented by adding phenylmethylsulphonyl fluoride $\left(15 \mu \mathrm{g} \mathrm{m}^{-1}\right)$ to the cell suspension $(80 \mathrm{~g}$ wet wt in $200 \mathrm{ml}$ of TCM buffer) before disruption. This was done in a Ribi Cell-Fractionator at $207 \mathrm{MPa}$ as described by Escamilla \& Benito (1984). Nondisrupted cells were removed by centrifugation at $1500 \mathrm{~g}$ for $5 \mathrm{~min}$ and membranes were pelleted from the supernatant by centrifugation at $144000 \mathrm{~g}$ for $45 \mathrm{~min}$; they were washed twice with TCM buffer under the same conditions. The membranes were used immediately for assay of enzymic activities.

Respiratory activities. Oxidoreductase and oxidase activities were determined as described by Escamilla \& Benito (1984). Succinate oxidoreductase was measured at $30^{\circ} \mathrm{C}$ in $3 \mathrm{ml}$ of a mixture containing $20 \mathrm{~mm}$-disodium succinate (pH 7.5), $50 \mathrm{mM}$-potassium phosphate ( $\mathrm{pH} 7.5$ ), $1.1 \mathrm{mM}$-phenazine methosulphate (PMS), 0.08 mMsodium 2,6-dichlorophenolindophenol (DCPIP), 0.1 mM-KCN, and membranes (0.25 mg protein). NADH oxidoreductase was measured under the same conditions except that succinate and PMS were replaced by $0.5 \mathrm{mM}$ NADH. An extinction coefficient of $21 \mathrm{~mm}^{-1} \mathrm{~cm}^{-1}$ at $600 \mathrm{~nm}$ was used for DCPIP.

Oxidase activities with NADH or succinate as substrates were estimated at $30^{\circ} \mathrm{C}$ in a model 52 Oxygen Meter (Yellow Spring Instruments). The reaction vessel contained $3 \mathrm{ml} 50 \mathrm{~mm}$-potassium phosphate (pH 7.4) and membranes ( $1.5 \mathrm{mg}$ protein); the reaction was started by the addition of $40 \mathrm{~mm}$-succinate or $0.5 \mathrm{~mm}$-NADH (final concentrations). Cytochrome $c$ oxidase was determined under the same conditions except that the $\mathrm{pH}$ was 6.8 and $10 \mathrm{mM}$-sodium ascorbate plus $0 \cdot 1 \mathrm{mM}$-TMPD were used as electron donors.

Spectral analysis of cytochromes. Membranes were suspended in $50 \mathrm{mM}-\mathrm{Tris} / \mathrm{HCl}$ buffer $(\mathrm{pH} 7 \cdot 4)$ containing $5 \mathrm{mM}-\mathrm{CaCl}_{2}, 5 \mathrm{mM}-\mathrm{MgCl}_{2}$ and $50 \%(\mathrm{v} / \mathrm{v})$ glycerol, and analysed in an SLM-Aminco DW-2c II spectrophotometer at room temperature $(1.0 \mathrm{~cm}$ light-path cuvettes) or under liquid nitrogen $(2.0 \mathrm{~mm}$ light path cuvettes). The concentrations of cytochromes were estimated from difference spectra (dithionite-reduced minus persulphateoxidized or dithionite $+\mathrm{CO}$ minus dithionite reduced) of membranes at room temperature. A spectral band width of $2.0 \mathrm{~nm}$ was used for spectra recorded at room temperature and $77 \mathrm{~K}$. The following wavelength pairs and absorption coefficients were used: cytochrome $a a_{3}, 603-630,16.6 \mathrm{~mm}^{-1} \mathrm{~cm}^{-1}$ (Sone, 1986); cytochrome $b$, $563-575,20 \mathrm{~mm}^{-1} \mathrm{~cm}^{-1}$ (De Vrij et al., 1983); cytochrome $c, 550-540,19 \mathrm{~mm}^{-1} \mathrm{~cm}^{-1}$ (De Vrij et al., 1983); cytochrome $a a_{3}-\mathrm{CO}, 590-605,8 \cdot 1 \mathrm{~mm}^{-1} \mathrm{~cm}^{-1}$ (Yoshida \& Fee, 1984); cytochrome o-CO, 415-430, $145 \mathrm{~mm}^{-1} \mathrm{~cm}^{-1}$ (Kita et al., 1984); cytochrome $d, 630-650,18.8 \mathrm{mM}^{-1} \mathrm{~cm}^{-1}$ (Kita et al., 1984).

\section{RESULTS AND DISCUSSION}

\section{Effect of carbon source and aeration on growth}

The growth properties of $B$. cereus in a medium containing sucrose/yeast extract or casein hydrolysate under different aeration conditions were examined. Under forced aeration, the fastest growth rate (generation time $28 \mathrm{~min}$ ) was obtained in the sucrose/yeast extract medium. When casein hydrolysate was the only carbon source, growth rate decreased significantly (generation time $60 \mathrm{~min}$ ). Limited aeration and anaerobiosis caused a dramatic drop of growth rate, generation times being $182 \mathrm{~min}$ and $290 \mathrm{~min}$ respectively, in sucrose/yeast extract medium. Supplementation of the medium with $0.15 \% \mathrm{NaNO}_{3}$ improved growth under anaerobic conditions (generation time $170 \mathrm{~min}$ ). Although a minor role in the generation of ATP has been assigned to the respiratory system of $B$. cereus during vegetative growth on fermentable carbon sources (Goldman \& Blumenthal, 1964), it seems that an adequate supply of oxygen is needed for fast growth. On the other hand, it has been postulated that anaerobic growth of other bacteria in the presence of $\mathrm{NO}_{3}^{-}$is limited by the accumulation of $\mathrm{NO}_{2}^{-}$(Meijer et al., 1979).

\section{Respiratory activities}

Dehydrogenase-and oxidase activities of membranes from cells grown under the conditions described above were compared (Table 1). Cells grown with vigorous aeration in medium 
Table 1. Respiratory activities and cytochromes in membranes of $B$. cereus grown under different culture conditions

SYE, sucrose/yeast extract medium; $\mathrm{CH}$, casein hydrolysate medium.

\begin{tabular}{|c|c|c|c|c|c|}
\hline \multirow[b]{3}{*}{ Medium ... } & \multirow{2}{*}{\multicolumn{2}{|c|}{$\underbrace{\text { Aerobic }}$}} & \multirow{3}{*}{$\overbrace{\text { SYE }}^{\text {Oxygen-limited }}$} & \multicolumn{2}{|c|}{ Anaerobic } \\
\hline & & & & SYE & SYE \\
\hline & SYE & $\mathrm{CH}$ & & $-\mathrm{NO}_{3}^{-}$ & $+\mathrm{NO}_{3}^{-}$ \\
\hline \multicolumn{6}{|l|}{ Dehydrogenase* } \\
\hline NADH & 55 & 150 & 45 & 32 & 40 \\
\hline Succinate & 86 & 360 & 80 & 71 & 94 \\
\hline \multicolumn{6}{|l|}{ Oxidase } \\
\hline NADH & 20 & 45 & 15 & 5 & 7.5 \\
\hline Succinate & 7.5 & 58 & 6 & 4 & $4 \cdot 5$ \\
\hline Ascorbate-TMPD & 17 & 38 & 10 & 7 & 5 \\
\hline \multicolumn{6}{|l|}{ Cytochrome $\dagger$} \\
\hline$b$ & $0 \cdot 12$ & 0.29 & $0 \cdot 18$ & 0.14 & 0.13 \\
\hline$c$ & 0.05 & $0 \cdot 15$ & 0.02 & 0.02 & 0.02 \\
\hline$a a_{3}$ & 0.072 & $0 \cdot 21$ & 0.03 & 0.01 & 0.02 \\
\hline$d$ & ND & 0.01 & 0.013 & 0.013 & ND \\
\hline$o \ddagger$ & 0.044 & $0 \cdot 154$ & 0.066 & 0.08 & 0.08 \\
\hline$a_{3} \ddagger$ & 0.05 & $0 \cdot 16$ & ND & ND & ND \\
\hline
\end{tabular}

ND, Not detected or too low to be calculated (see Figs 2 and 3).

* Dehydrogenase activity is expressed as nmol DCPIP reduced $\min ^{-1}$ (mg membrane protein $)^{-1}$. Values are means of three different cultures. The SD values were less than $15 \%$ of the figures given.

+ Cytochrome concentration are given as nmol (mg membrane protein) ${ }^{-1}$ and were calculated from (dithionitereduced minus persulphate-oxidized) or (dithionite-reduced + $\mathrm{CO}$ minus dithionite-reduced) difference spectra at room temperature. The wavelength pairs and millimolar absorption coefficients given in Methods were used. Data are means of at least four different cultures. The SD values were less than $20 \%$ of the figures given.

$\ddagger$ Measured in CO difference spectra.

supplemented with casein hydrolysate exhibited the highest levels of NADH and succinate oxidoreductases as well as oxidase activities for NADH, succinate and ascorbate plus TMPD. In contrast, cells cultured in well-aerated sucrose/yeast extract medium exhibited significantly lower activities (Table 1); the availability of a fermentable carbon source, such as sucrose, may repress the respiratory system. Significantly lower activities were obtained when oxygen was limited or excluded (Table 1) during culture in sucrose yeast extract medium.

\section{Cytochromes}

Oxygen tension and the nature of the carbon source in culture media had marked effects on the expression of the cytochrome system of B. cereus (Figs 1 and 2). As reported previously (Escamilla \& Benito, 1984) the dithionite-reduced minus persulphate-oxidized spectra at $77 \mathrm{~K}$ of membranes from cells grown in well-aerated sucrose/yeast extract medium (Fig. $1 a$ ) showed the presence of cytochrome $b$ with a maximum at $559 \mathrm{~nm}$ and a shoulder at $562 \mathrm{~nm}$ tentatively identified as cytochrome $o$. A shoulder at $550 \mathrm{~nm}$ for cytochrome $c$ was also seen, while cytochrome $a a_{3}$ was well-defined at $601 \mathrm{~nm}$. Absorbance at $632 \mathrm{~nm}$, which would have suggested the presence of cytochrome $d$, was not observed. On the other hand, a clear peak at $632 \mathrm{~nm}$ was present in membranes of cells grown in well-aerated casein hydrolysate medium as well as in oxygen-limited and anaerobic cultures in sucrose/yeast extract medium (Fig. $1 b-d)$. The addition of $0.15 \% \mathrm{NaNO}_{3}$ to the anaerobic cultures interfered with the expression of cytochrome $d$ (Fig. 1e), in agreement with work on Haemophilus parainfluenzae (Sinclair \& White, 1970), in which it was shown that $\mathrm{NO}_{3}^{-}$represses the anaerobic expression of cytochrome $d$. A lowering of the oxygen tension in the culture produced a drastic drop in the content of cytochromes $a a_{3}$ (Fig. 1 c). This has been reported for other bacteria containing cytochrome $a a_{3}$ 


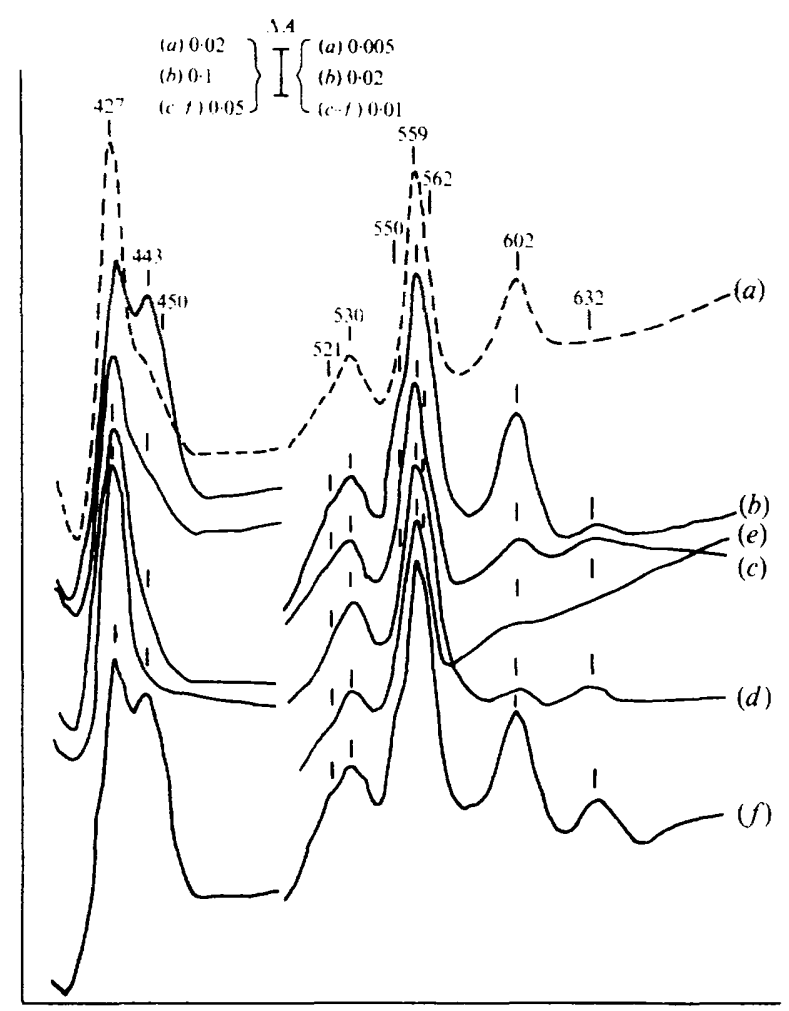

Fig. 1. Difference spectra (dithionite-reduced minus persulphate-oxidized) of membranes from vegetative cells cultured under different conditions: $(a)$ aerobic growth in sucrose/yeast extract medium; $(b)$ aerobic growth in casein hydrolysate medium; $(c)$ oxygen-limited growth in sucrose/yeast extract medium; $(d)$ anaerobic growth in sucrose/yeast extract medium; $(e)$ anaerobic growth in sucrose/yeast extract medium supplemented with $0.15 \% \mathrm{NaNO}_{3} ;(f)$ aerobic growth in casein hydrolysate medium supplemented with $0.1 \mathrm{~mm}-\mathrm{KCN}$. Spectra were recorded at $77 \mathrm{~K}$. Membrane protein concentrations were as follows $\left(\mathrm{mg} \mathrm{ml}^{-1}\right):(a) 13 ;(b) 7.5 ;(c-f) 12$.

(Poole, 1983). Under anaerobic conditions, only trace amounts of cytochrome $a a_{3}(602 \mathrm{~nm}$ peak) were detected (Fig. 1d,e), whereas the peak height of cytochrome $b(559 \mathrm{~nm})$ was not significantly affected by the oxygen tension (Fig. $1 c, d, e$ ). Cells cultured in casein hydrolysate medium under forced aeration contained diverse cytochromes at high concentrations (Fig. $1 b$ ). Interestingly, levels of cytochrome $d$ in these cells increased on addition of $0.25 \mathrm{~mm}-\mathrm{KCN}$ to the culture (Fig. $1 \mathrm{f}$ ); this is in agreement with previous reports in other bacteria containing cytochrome $d$ (Ashcroft \& Haddock, 1975).

The $\mathrm{CO}$ difference spectra (Fig. 2) of dithionite-reduced membranes revealed the presence of a CO-complex resembling that of cytochrome $o$, with a peak at $575 \mathrm{~nm}$, a peak at $540 \mathrm{~nm}$ and a Soret peak at $419 \mathrm{~nm}$. The troughs appeared at $560 \mathrm{~nm}$ and $430 \mathrm{~nm}$. This CO-complex was present in cells grown under all the conditions studied (Fig. $2 a-e$ ). Increased concentrations of this presumptive cytochrome $o$ were found in cells grown in well-aerated casein hydrolysate medium and oxygen-limited sucrose/yeast extract medium (Fig. 2b,c). In contrast, cytochrome $a a_{3}$, measured as its CO-complex (445 nm trough, $592 \mathrm{~nm}$ peak), fell dramatically in cells cultured at low oxygen tensions or anaerobically (Fig. $2 c-e$ ).

It is known that the reduced peak of cytochrome $d$ at $632 \mathrm{~nm}$ is shifted to higher wavelengths on bubbling with $\mathrm{CO}$ (Poole, 1983). This peak was observed at $639 \mathrm{~nm}$ in cells grown in aerobic casein hydrolysate medium, as well as in cells obtained from oxygen-limited and anaerobic sucrose yeast extract medium (Fig. $2 b-d$ ). The cytochrome $d$-CO complex was not detected in anaerobic cultures supplemented with $0.15 \% \mathrm{NaNO}_{3}$ (Fig. $2 e$ ). 


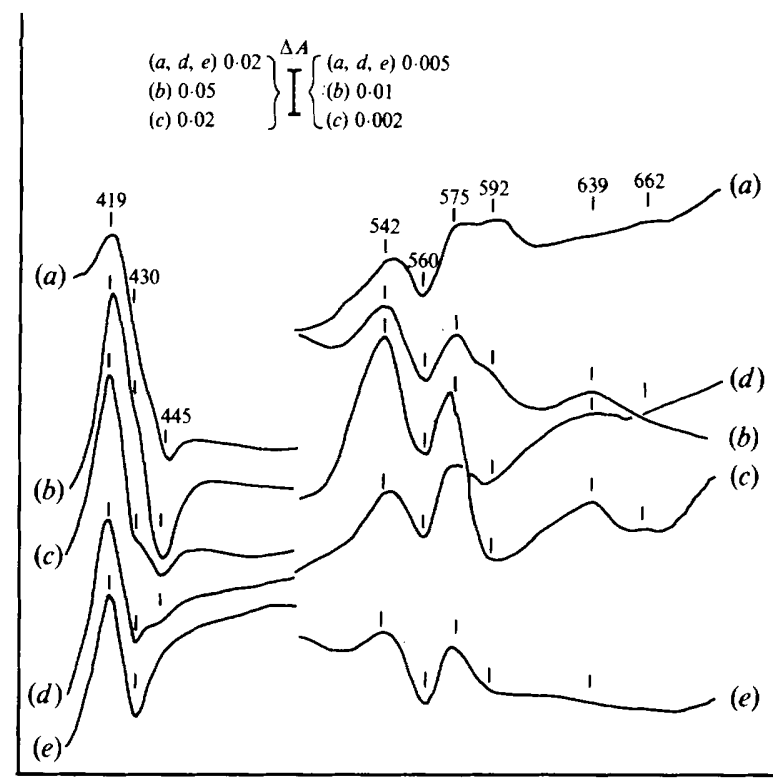

Fig. 2. CO difference spectra of dithionite-reduced membranes of vegetative cells cultured as follows: (a) aerobically in sucrose/yeast extract medium; (b) aerobically in casein hydrolysate medium; (c) under oxygen-limited conditions in sucrose/yeast extract medium; $(d)$ anaerobically in sucrose/yeast extract medium; (e) anaerobically in sucrose/yeast extract medium supplemented with $0.15 \% \mathrm{NaNO}_{3}$. Membrane suspensions were reduced with a few grains of dithionite, mixed thoroughly and divided into two equal portions. Contents of sample cuvettes were bubbled with $\mathrm{CO}$ for $5 \mathrm{~min}$ and subsequently the spectra were recorded at room temperature. Membrane protein concentrations were as follows $\left(\mathrm{mg} \mathrm{ml}^{-1}\right):(a, d$ and $e$ ) $12 ;(b) 7 \cdot 5 ;(c) 8.5$.

The addition of NADH, succinate or ascorbate plus TMPD to membranes from cells cultured under all the conditions described showed qualitatively the same reduction pattern (data not shown) obtained with dithionite (Fig. 1). Notably, cytochrome $a a_{3}(602 \mathrm{~nm})$, a cytochrome $b$ $(562 \mathrm{~nm})$ and cytochrome $d(632 \mathrm{~nm})$ were detected regardless of the substrate used for reduction.

The concentrations of each of the cytochromes were calculated (Table 1). Cells grown under vigorous aeration in casein hydrolysate medium contained cytochromes at the highest concentrations. Lowering the oxygen tension of the culture decreased the concentrations of cytochromes $a a_{3}$ and $c$, whereas the concentrations of cytochromes $b, o$ and $d$ increased significantly.

The effect of cyanide on substrate-dependent respiration (Fig. 3) was determined for membranes prepared from cells cultured under the various conditions described. The oxidation of ascorbate plus TMPD by aerobic cells grown in casein hydrolysate medium was inhibited $80 \%$ by $20 \mu \mathrm{M}-\mathrm{KCN}$. This concentration caused $50 \%$ inhibition of respiration in aerobic cells grown in sucrose/yeast extract medium, and about $20 \%$ inhibition in membranes of oxygenlimited and anaerobically grown cells. Thus, those cells that contained the highest respiratory activities were the most sensitive to cyanide.

Oxygen-limited and anaerobically grown cells that contained low levels of cytochromes $a a_{3}$ and $c$ and exhibited a low capacity to oxidize ascorbate plus TMPD (Table 1) were more resistant to cyanide. Indeed, all cell types showed a certain proportion of cyanide-insensitive TMPD oxidase (Fig. 3). This cyanide-resistant respiration was most apparent when NADH was the substrate. In the case of cells grown anaerobically in the presence of $\mathrm{NO}_{3}^{-}$this cyanide resistance could not be correlated with the detection of cytochrome $d$ (Fig. 1e). However, Hoggarth et al. (1977) in B. megaterium and Escamilla \& Benito (1984) in B. cereus demonstrated 


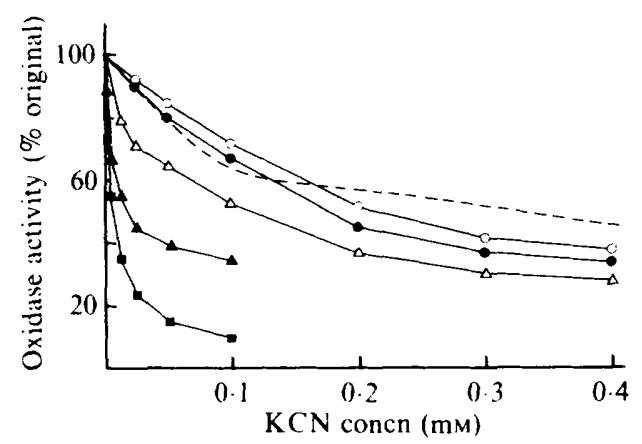

Fig. 3. Effect of cyanide on ascorbate-TMPD oxidase activity of membranes of $B$. cereus cultured aerobically in casein hydrolysate medium ( $\square$ ), aerobically in sucrose/yeast extract medium $(\boldsymbol{A})$, under oxygen-limited conditions in sucrose/yeast extract medium $(\triangle)$, anaerobically in sucrose/yeast extract medium (O) and anaerobically in sucrose/yeast extract medium supplemented with $0.15 \% \mathrm{NaNO}_{3}$ (O). - - NADH oxidase activity of cells grown aerobically in casein hydrolysate medium. Membranes $\left(1.0 \mathrm{mg}\right.$ protein) were preincubated $\left(3 \mathrm{~min}\right.$ at $\left.30^{\circ} \mathrm{C}\right)$ with the indicated $\mathrm{KCN}$ concentrations. The reaction was started by addition of substrate.

(in cyanide difference spectra at $77 \mathrm{~K}$ ) that the putative cytochrome $o(562 \mathrm{~nm}$ peak) remains oxidized by air, while cytochromes $c$ and $a a_{3}$ show almost complete reduction. Thus, it is possible that both cytochrome $o$ and cytochrome $d$ play a role in the cyanide-resistant respiration of $\boldsymbol{B}$. cereus and $\boldsymbol{B}$. megaterium. The expression of cytochrome $d$ in $\boldsymbol{B}$. cereus was in agreement with its pattern of regulation reported in other bacteria. Its appearance (Figs 1 and 2) is enhanced by low oxygen tensions (Scott \& Poole, 1982), aerobic growth on slowly metabolizable carbon sources (Haddock et al., 1976; Sweet \& Peterson, 1978) and during anaerobic growth (Haddock et al., 1976), and is repressed by the inclusion of $\mathrm{NO}_{3}^{-}$during anaerobic growth (Sinclair \& White, 1970). The presence of cytochrome $d$ in Bacillus spp. was suggested by Taber (1974), who detected a new absorbance maximum at $627 \mathrm{~nm}$ (reduced minus oxidized spectra) in mutants of $B$. subtilis lacking cytochrome $a$; Hoggarth et al. (1977) proposed the presence of cytochrome $d$ in B. megaterium. Studies on B. cereus ATCC 4342 (Felix \& Lundgren, 1973) and a highly cyanide resistant strain of $B$. cereus (Mc. Fetters et al., 1970) showed a discrete absorbance around $630 \mathrm{~nm}$.

The role of cytochromes $a a_{3}$ and $o$ as terminal oxidases has been demonstrated in aerobically grown cells of B. subtilis (Edwards et al., 1981) and in the thermophilic bacterium PS3 (Poole et $a l ., 1982$ ). Such studies remain to be done on $B$. cereus and $B$. megaterium.

This work was supported by grant PCCBNA-022646 from Consejo Nacional de Ciencia y Tecnologia, México. We express our deep appreciation to A. Gómez Puyou and A. Peña for their generous help and criticism during the preparation of this manuscript.

\section{REFERENCES}

ANdreoli, A. J., Sulhiro, S., SAkiyama, D., Takemoto, J., Vivanco, E., Lara, J. C. \& Klute, M. C. (1973). Release and recovery of forespore of Bacillus cereus. Journal of Bacteriology 115, 1159-1166.

AShCroft, J. R. \& Haddock, B. A. (1975). Synthesis of alternative membrane-bound redox carriers during aerobic growth of Escherichia coli in the presence of potassium cyanide. Biochemical Journal 148, 349352.

Broberg, P. L. \& SMith, L. (1967). The cytochrome system of Bacillus megaterium KM. The presence and properties of two CO-binding cytochromes. Biochimica et biophysica acta 131, 479-489.
DE VRIJ, W., AzZI, A. \& Konings, N. (1983). Structural and functional properties of cytochrome $c$ oxidase from Bacillus subtilis W23. European Journal of Biochemistry 131, 97-103.

Edwards, C., Beer, S., Siviram, A. \& Chance, B. (1981). Photochemical action spectra of bacterial $a$ and $o$-type oxidases using a dye laser. FEBS Letters 28, 205-207

Escamilla, J. E. \& Benito, M. C. (1984). Respiratory system of vegetative and sporulating Bacillus cereus. Journal of Bacteriology 160, 473-477.

Felix, J. A. \& LundGren, D. G. (1973). Electron transport system associated with membranes of 
Bacillus cereus during vegetative growth and sporulation. Journal of Bacteriology 15, 552-559.

Goldman, M. \& Blumenthal, H. J. (1964). Changes in terminal respiratory pathways of intact cells of Bacillus cereus at various stages of development. Journal of Bacteriology 87, 387-390.

Haddock, B. A., Downie, J. A. \& Garland, P. B. (1976). Kinetic characterization of the membrane bound cytochromes of Escherichia coli grown under a variety of conditions by using a stopped-flow dual wavelength spectrophotometer. Biochemical Journal 154, 285-290.

Hanson, R. S., Srinivasan, V. R. \& Halvorson, H. O. (1963). Biochemistry of sporulation. I. Metabolism of acetate by vegetative and sporulating cells. Journal of Bacteriology 85, 451-460.

Hoggarth, C., Wilkinson, B. J. \& Ellar, D. J. (1977). Cyanide resistant electron transport in sporulating Bacillus megaterium KM. Biochimica et biophysica acta 461, 109-123.

KITA, K., Konishi, K. \& ANRAKU, Y. (1984). Terminal oxidases of Escherichia coli aerobic respiratory chain. I. Purification and properties of cytochrome $b_{562}-o$ complex from cells in the early exponential phase of aerobic growth. Journal of Biological Chemistry 259, 3368-3374.

Mc. Fetters, G. A., Wilson, D. F. \& Strobel, G. A. (1970). Cytochromes in a cyanide-resistant strain of Bacillus cereus. Canadian Journal of Microbiology 16, 1221-1226.

MEJjer, E. M., VAN der ZWAan, J. W., WeVer, R. \& Stouthamer, A. H. (1979). Anaerobic respiration and energy conservation in Paracoccus denitrificans. Functioning of iron-sulfur centers and the uncoupling effect of nitrite. European Journal of Biochemistry 96, 69-75.

Poole, R. K. (1983). Bacterial cytochrome oxidases. A structurally and functionally diverse group of electron-transfer proteins Biochimica et biophysica acta 726, 205-243.

Poole, R. K., Scott, R. I., Baines, B. S., SAlmon, I. \& LLOYD, D. (1982). Identification of cytochromes $o$ and $a_{3}$ as functional terminal oxidases in the thermophilic bacterium, PS3. FEBS Letters 150, 281-284.

SCOT, R. I. \& POOLE, R. K. (1982). A re-examination of the cytochromes of Escherichia coli using fourthorder finite differences analysis: their characterization under different growth conditions and accumulation during the cell cycle. Journal of General Microbiology 128, 1685-1696.

Sinclair, P. R. \& White, D. C. (1970). Effect of nitrate, fumarate and oxygen on the formation of the membrane-bound electron transport system of $\mathrm{Hae}$ mophilus parainfluenzae. Journal of Bacteriology 101, 365-372.

SONE, N. (1986). Cytochrome oxidase from thermophilic bacterium PS3. Methods in Enzymology 126, 145-153.

Sterlini, J. M. \& Mandelstam, J. (1969). Commitment to sporulation in Bacillus subtilis and its relationship to development of actinomycin resistance. Biochemical Journal 113, 29-37.

TABER, H. (1974). Isolation and properties of cytochrome a-deficient mutants of Bacillus subtilis. Journal of General Microbiology 81, 435-444.

TоCHIKUBO, K. (1971). Changes in terminal respiratory pathways of Bacillus subtilis during germination, outgrowth and vegetative growth. Journal of Bacteriology 108, 652-661.

YoshIDA, T. \& FEE, J. A. (1974). Studies on cytochrome $c$ oxidase activity of the cytochrome $c_{1}-a a_{3}$ complex from Thermus thermophilus. Journal of Biological Chemistry 259, 1031-1036. 